Revista Brasileira de Cartografia

ISSN 1808-0936 | https://doi.org/10.14393/revbrascartogr

Sociedade Brasileira de Cartografia, Geodésia, Fotogrametria e Sensoriamento Remoto

\title{
Discriminação de Classes de Cobertura Vegetal em uma Região de Transição Amazônia/Cerrado no Estado de Mato Grosso por meio de Imagens do Satélite ALOS-2/PALSAR-2
}

\section{Discriminating Vegetation Cover Classes of an Amazon/Cerrado Transition Region in the Mato Grosso State Using ALOS-2/PALSAR-2 Satellite Images}

\author{
Vanessa Souza Silva ${ }^{1}$, Edson Eyji Sano ${ }^{2}$, Tati de Almeida ${ }^{3}$ e Humberto Navarro de Mesquita Júnior 4
}

1 Universidade de Brasília, Programa de Pós-Graduação em Geociências Aplicadas e Geodinâmica, Brasília, Brasil. E-mail: vanessa.geosensoremoto@gmail.com.

ORCID: https://orcid.org/0000-0002-1726-7401

2 Embrapa Cerrados, Planaltina, Brasil. E-mail: edson.sano@embrapa.br.

ORCID: https://orcid.org/0000-0001-5760-556X

3 Universidade de Brasília, Instituto de Geociências, Brasília, Brasil. E-mail: tati_almeida@unb.br.

ORCID: https://orcid.org/0000-0002-6387-8254

4 Serviço Florestal Brasileiro, Gerência de Cadastro de Florestas Públicas, Brasília, Brasil.

E-mail: humberto.mesquita@ florestal.gov.br.

ORCID: https://orcid.org/0000-0002-1718-9204

Resumo: A região de transição entre Amazônia e Cerrado, especialmente no estado de Mato Grosso, é bastante sensível em termos ambientais por causa da elevada biodiversidade e alta produção de grãos e carne bovina. O objetivo deste estudo foi discriminar classes representativas de uso e cobertura de terras encontradas na região de Sinop/Mato Grosso com base nas imagens de radar do satélite ALOS-2/PALSAR-2. As seguintes classes temáticas foram consideradas: floresta primária; floresta secundária; cultura agrícola; e pastagem cultivada. As imagens foram obtidas nos meses de fevereiro (estação chuvosa) e setembro (estação seca) de 2016, com resolução espacial de 6,25 metros, polarizações HH e HV e banda L (comprimento de onda de $23 \mathrm{~cm}$ ), as quais foram processadas pelos algoritmos de classificação supervisionada Random Forest (RF) e Support Vector Machine (SVM). Amostras de treinamento e de validação (65 amostras) foram obtidas em campo e complementadas com base nos mapas de uso e cobertura de terras produzidos pelos projetos MapBiomas e TerraClass Amazônia (135 amostras). Foi possível discriminar dois grupos de classes temáticas: floresta primária e floresta secundária; e cultura agrícola e pastagem cultivada. Apesar da acurácia global do RF ter sido superior ao do SVM, os dois classificadores mostraram desempenhos estatisticamente similares.

Palavras-chave: Radar de Abertura Sintética. Banda L. Sensoriamento Remoto.

\begin{abstract}
The transition region between Amazonia and Cerrado, especially in the Mato Grosso State, is environmentally sensitive because of the high levels of biodiversity and high grain and cattle beef productions. The objective of this study was to discriminate representative land use and land cover (LULC) classes found in the Sinop/Mato Grosso region based on the ALOS-2/PALSAR-2 satellite images. The following thematic classes were considered: primary forest, secondary forest, croplands, and cultivated pasturelands. The scenes were obtained in February (rainy season) and September (dry season) of 2017, with spatial resolution of $6.25 \mathrm{~m}$, HH and HV polarizations, and L-band (wavelength of $23 \mathrm{~cm}$ ) and processed by the Random Forest (RF) and Support Vector Machine (SVM) classifiers. Training and validation samples were obtained in the field (65 samples) and complemented based on the LULC maps produced by the MapBiomas and TerraClass projects (135 samples). It was possible to discriminate two groups of thematic classes: primary forest and secondary forest; and croplands and pasturelands. Although the overall accuracy of RF was higher than that from SVM, both classifiers presented statistically similar performances.
\end{abstract}

Keywords: Synthetic Aperture Radar. L-Band. Remote Sensing. 


\section{INTRODUÇÃO}

O estado de Mato Grosso, com uma área de aproximadamente $903 \mathrm{mil} \mathrm{km}^{2}$, é coberto pelo bioma Amazônia na porção norte (54\% da área total do estado), Cerrado na porção central (40\%) e Pantanal na porção sul (6\%) (IBGE, 2004). Cerrado e Pantanal são considerados hotspots para conservação da biodiversidade (MYERS et al., 2000), enquanto o bioma Amazônia é considerado área selvagem, isto é, região com mais de 1 milhão de hectares, mais da $70 \%$ da área preservada e densidade populacional inferior a 5 habitantes por $\mathrm{km}^{2}$ (MITTERMEIER et al., 2003). Segundo o atual Código Florestal Brasileiro (Lei Federal no. 12.651 de 25 de maio de 2012), imóveis rurais situados em áreas de florestas da Amazônia Legal devem manter 80\% da propriedade rural com cobertura de vegetação nativa. Os imóveis localizados em área de Cerrado no estado de Mato Grosso devem manter 35\% do imóvel com vegetação nativa, enquanto os localizados em outras áreas do País devem preservar 20\%. Além disso, áreas consideradas como de preservação permanente, tais como as áreas ao longo das drenagens ou ao redor das nascentes, também devem permanecer com cobertura vegetal natural (SOARES-FILHO et al., 2014). Ao longo das drenagens, as faixas de preservação variam de $30 \mathrm{~m}$ para cursos d'água com menos de $10 \mathrm{~m}$ de largura a $500 \mathrm{~m}$ para cursos d'água com mais de $600 \mathrm{~m}$ de largura. Ao redor das nascentes, a área de preservação engloba um raio mínimo de $50 \mathrm{~m}$.

Apesar dessas restrições no uso de terras no estado de Mato Grosso e no estabelecimento de um acordo entre produtores, sociedade civil e governo federal para inibir o avanço da soja na Amazônia em áreas de floresta nativa, conhecido como Moratória da Soja (GIBBS et al., 2015; KASTENS et al., 2017; GOLLNOW et al., 2018; SILVA JÚNIOR; LIMA, 2018), são encontrados 9,7 milhões de hectares de culturas agrícolas anuais e 19,0 milhões de hectares de pastagens cultivadas nesse estado, o que corresponde a $17 \%$ da área total de culturas agrícolas anuais e de pastagens cultivadas encontradas no País (IBGE, 2017a). O estado do Mato Grosso é o principal produtor de soja e carne bovina do Brasil, respondendo por $27 \%$ da produção nacional de soja e por $14 \%$ do total de bovinos (IBGE, 2017b, c). Os setes municípios com as maiores áreas de culturas anuais (Sorriso, Nova Mutum, Campo Novo do Parecis, Sapezal, Querência, Nova Ubiratã e Diamantino) localizam-se na região central do estado, mais especificamente, na região de transição entre os biomas Amazônia e Cerrado.

Dentro desse contexto, o estado de Mato Grosso, em especial, a região de transição Amazônia/Cerrado, merece uma atenção especial em termos de monitoramento da dinâmica de uso e cobertura de terras, pois ela se constitui em uma frente de expansão agrícola para o interior da Amazônia brasileira, por exemplo, para as regiões de Novo Progresso e Santarém no estado do Pará, localizadas ao longo da rodovia federal BR-163, também conhecida como rodovia Cuiabá-Santarém. Estudos anteriores sobre o monitoramento de uso e cobertura de terras envolvendo corte raso e discriminação de tipos de culturas agrícolas anuais ou de identificação de áreas com degradação florestal por corte seletivo no estado de Mato Grosso têm sido conduzidos principalmente com base na análise de imagens ópticas dos satélites da série Landsat (e.g., SHIMABUKURO et al., 2014; MÜLLER et al., 2016; MÜLLER; GRIFFITHS; HOSTERT, 2016; ZHU et al., 2016; GRIFFITHS; JAKIMOW; HOSTERT, 2018) e do sensor Moderate Resolution Imaging Spectroradiometer (MODIS) (e.g., ARVOR et al., 2011; MACEDO et al., 2012; VICTORIA et al., 2012; BROWN et al., 2013; PICOLI et al., 2018).

Devido à cobertura persistente de nuvens sobre a região amazônica (ASNER, 2001; MARTINS et al., 2018), muitos autores têm utilizado imagens obtidas por radar para fins de monitoramento ambiental e identificação de atividades antrópicas nessa região. Além da capacidade de imageamento independentemente da presença de nuvens, as imagens de radar fornecem informações de natureza geométrica e dielétrica baseadas em diferenças na rugosidade do terreno, estrutura da vegetação e conteúdo de água no solo e nas plantas. Tais informações são complementares às obtidas por sensores ópticos, que são baseadas principalmente em composição química dos elementos constituintes dos solos, rochas e plantas (SANO; MENESES; ALMEIDA, 2019).

Uma variedade de estudos utilizando imagens de radar tem sido realizada para detectar áreas desmatadas na Amazônia (e.g., ALMEIDA-FILHO et al., 2005, 2009; ABOUD NETA; FREITAS; DUTRA, 2010; PEREIRA et al., 2016; CARREIRAS et al., 2017; PÔSSA et al., 2018; WATANABE et al., 2018; WIEDERKEHR et al., 2019; PULELLA et al., 2020). Essa ênfase é decorrente, por exemplo, da grande 
preocupação em monitorar o desmatamento na Amazônia durante a estação chuvosa. Dados de indicativos de desmatamento da Amazônia Legal produzidos pelo sistema JICA-JAXA Forest Early Warning System in the Tropics (JJ-FAST, 2019) no período de maio a dezembro de 2018 apontam que a maior parte do desmatamento na Amazônia ocorre durante o período chuvoso: 898 e 1.056 áreas de desmatamento detectadas em novembro e dezembro - estação chuvosa -, respectivamente, contra 492 e 408 áreas detectadas em agosto e setembro estação seca. Na estação seca, definida entre os meses de abril a setembro, predominam as atividades de queima de galhos e troncos deixados no terreno durante o processo de corte raso na estação chuvosa.

Atualmente, sistemas orbitais de radar operam nos comprimentos de onda denominados de bandas $\mathrm{X}$ (comprimento de onda em torno de $3 \mathrm{~cm}$ ), C (em torno de $5 \mathrm{~cm}$ ) e L (em torno de $23 \mathrm{~cm}$ ). Exemplos de satélites que operam na banda X são o COSMO SkyMED da Itália e o TanDEM-X da Alemanha, na banda C são o RADARSAT-2 do Canadá e o Sentinel-1 da Agência Espacial Europeia (ESA) e na banda L são o ALOS-2 do Japão e o SAOCOM da Argentina. Para identificar mudanças de cobertura vegetal em áreas florestais, as imagens obtidas na banda $L$ apresentam um potencial maior por causa da maior capacidade de penetração da radiação incidente no dossel vegetal e nos solos (WOODHOUSE et al., 2012; LAPINI et al., 2020).

O objetivo deste estudo é analisar o potencial das imagens obtidas pelo satélite japonês Advanced Land Observing Satellite Phased Array type L-band Synthetic Aperture Radar (ALOS-2/PALSAR-2) para discriminar classes de uso e cobertura de terras de uma região de transição entre os biomas Amazônia e Cerrado localizada no estado de Mato Grosso. Essa região localiza-se próximo à sede do município mato-grossense de Sinop e próximo à rodovia BR-163, onde predominam as florestas estacionais semideciduais, culturas agrícolas de sequeiro, notadamente, soja, milho e algodão, e pastagens cultivadas, além de vegetação secundária, em menor proporção. O material básico deste estudo foram as imagens de radar do satélite ALOS2/PALSAR-2, das estações seca e chuvosa, obtidas no modo de imageamento StripMap, com resolução espacial de 6 metros e polarizações HH e HV. Essas imagens foram processadas pelos classificadores Random Forest (RF) e Support Vector Machine (SVM).

Além desta seção introdutória, o artigo apresenta detalhamento da área de estudo na Seção 2 e uma descrição dos materiais básicos e da abordagem metodológica na Seção 3. Os resultados são apresentados e discutidos na Seção 4, com inclusão do resultado da classificação supervisionada pelo método do SVM e uma análise de acurácia baseada em matriz de confusão, enquanto as principais conclusões são mostradas na Seção 5 .

\section{2 ÁREA DE ESTUDO}

A área de estudo selecionada possui uma extensão aproximada de $9.135 \mathrm{~km}^{2}$ e engloba, total ou parcialmente, nove municípios da microrregião mato-grossense de Sinop: Cláudia, Feliz Natal, Itaúba, Marcelândia, Nova Santa Helena, Santa Carmem, Sinop, União do Sul e Vera (Figura 1). Essa microrregião faz parte das áreas de influência da rodovia BR-163, que por sua vez fez parte do projeto estratégico para ocupação do Centro-Oeste e da Amazônia (ALENCAR et al., 2011). Trata-se de uma região com economia baseada no agronegócio, com fazendas de gado e monoculturas de soja, milho e algodão e retirada ilegal de madeiras nobres.

De acordo com os dados do projeto RADAMBRASIL (IBGE, 2018), a vegetação predominante da região é a floresta estacional semidecidual submontana. Conforme a classificação climática de Köppen-Geiger (KÖPPEN, 1936), o clima da região é tropical monçônico (Am), isto é, clima quente e úmido, com temperatura média anual de $24^{\circ}$, com baixa precipitação entre os meses de maio a setembro (precipitação mínima mensal de $0 \mathrm{~mm}$ ) e maior precipitação nos meses restantes (precipitação máxima mensal de $370 \mathrm{~mm}$ ). 
Figura 1 - Localização da área de estudo no estado de Mato Grosso (A) e na microrregião de Sinop (B). Recorte de imagem (C) corresponde à composição colorida RGB das bandas 6, 5 e 4 do satélite Landsat-8/OLI, obtida em 25 de agosto de 2016.

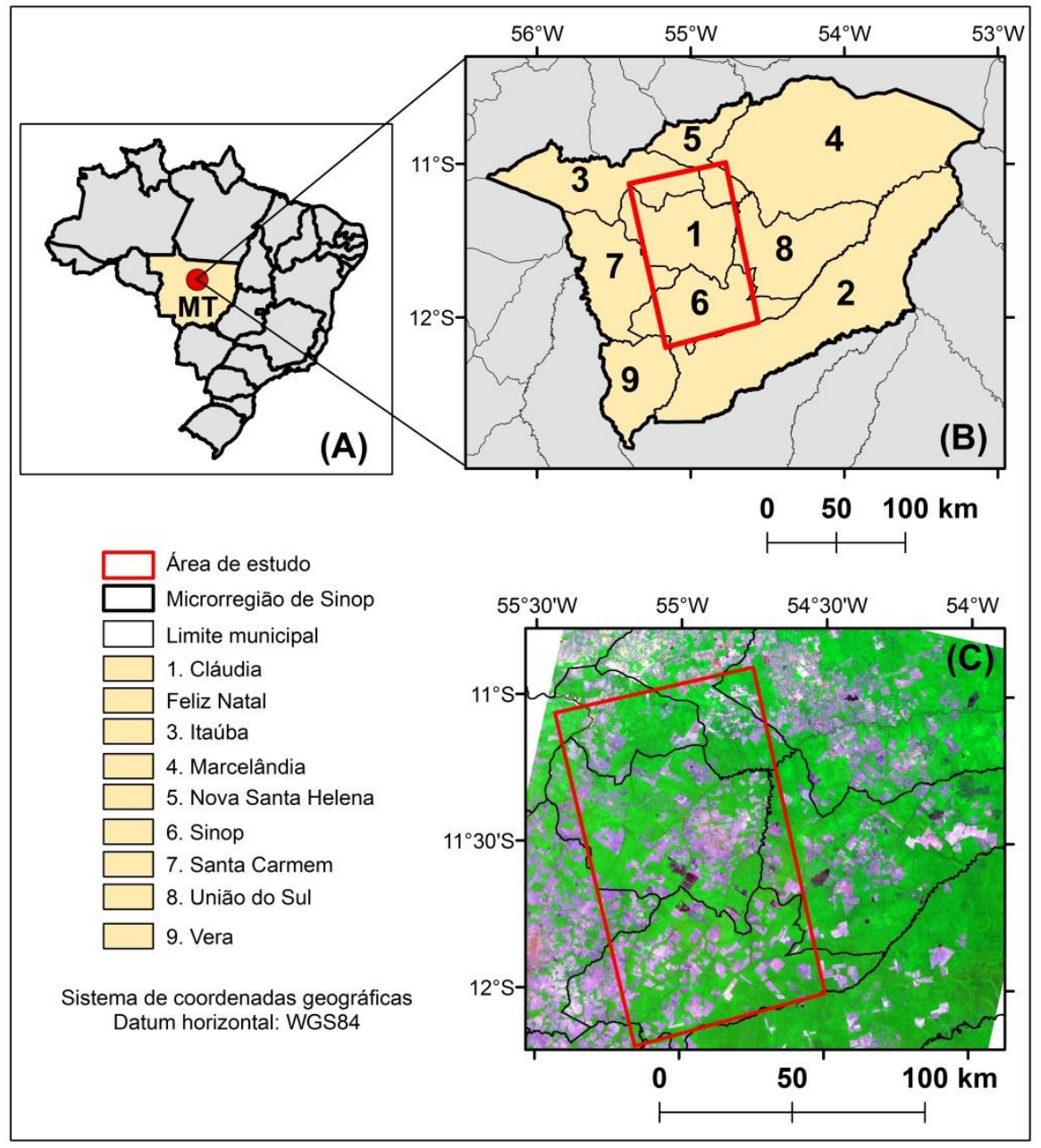

Fonte: Os autores (2021).

\section{MATERIAIS E MÉTODOS}

\subsection{Imagens do satélite ALOS-2/PALSAR-2}

Foram obtidas, no âmbito da Iniciativa Kyoto \& Carbono da Agência de Exploração Aeroespacial do Japão (JAXA) (ROSENQVIST et al., 2010), dois conjuntos de imagens do satélite ALOS-2/PALSAR-2 de 12 de fevereiro de 2016 e 23 de setembro de 2016, centrados nos municípios mato-grossenses de Cláudia e Sinop. Esse satélite corresponde ao segundo satélite da série ALOS e foi lançado em 24 de maio de 2014 para assegurar continuidade na obtenção de dados de radar de abertura sintética na banda L (ROSENQVIST et al., 2014).

O primeiro satélite operava com periodicidade de 46 dias e com três modos de imageamento: polarimétrico, fino e ScanSAR. A periodicidade do ALOS-2 foi mantida em 46 dias, porém, houve melhora nas resoluções espaciais dos modos de imageamento, em relação ao satélite predecessor: polarimétrico passou de $30 \mathrm{~m}$ para $3 \mathrm{~m}$; o modo fino passou de $10 \mathrm{~m}$ ou $20 \mathrm{~m}$ para $3 \mathrm{~m}, 6 \mathrm{~m}$ ou $10 \mathrm{~m}$; e o ScanSAR passou de uma única opção de $100 \mathrm{~m}$ para duas opções, $60 \mathrm{~m}$ ou $100 \mathrm{~m}$.

As imagens foram obtidas no modo StripMap (polarizações HH e HV, resolução espacial de 6,25 m e faixa de imageamento de $70 \mathrm{~km}$ ), com nível de processamento 1.1, ângulo de incidência médio de $34,3^{\circ}$ no centro da imagem, resolução radiométrica de 16 bits e formato CEOS. As precipitações acumuladas de 10 dias anteriores à obtenção das imagens foram de $21 \mathrm{~mm}$ e $72 \mathrm{~mm}$ em fevereiro e setembro, respectivamente, segundo dados da estação meteorológica automática de Sinop/MT (AGRITEMPO, 2018). 


\subsection{Abordagem metodológica}

A Figura 2 mostra o fluxograma das principais etapas de trabalho deste estudo, compostas basicamente por: a) seleção de cenas das estações seca e chuvosa; b) pré-processamento das cenas; c) aquisição de amostras de treinamento e validação; d) análise exploratória de dados baseado na análise de boxplots; e) classificação supervisionada de imagens; e f) análise de acurácia dos resultados da classificação.

O pré-processamento das cenas foi realizada no programa Sentinel Application Platform (SNAP) da ESA e envolveu as etapas de calibração radiométrica, filtragem multilook, filtragem do ruído speckle, conversão de unidade linear para retroespalhamento (decibéis, $\mathrm{dB}$ ) e ortorretificação por meio do modelo digital de elevação Shuttle Radar Topography Mission (SRTM) de 30 m de resolução espacial. As cenas foram projetadas para o sistema de projeção Universal Transversa de Mercator (UTM), fuso 21S e datum WGS84.

Para reduzir o ruído speckle, foram testados os filtros espaciais Lee, Frost, Gamma e Kuan, com diferentes janelas móveis ( 3 x 3, 5 x 5 e 7 x 7). O que apresentou o melhor resultado visual em termos de preservação da textura e dos contornos dos alvos foi o filtro adaptativo Gamma Map com janela de $3 \times 3$. Os filtros adaptativos atuam no sentido de minimizar a variância dos coeficientes de retroespalhamento dos pixels localizados em regiões homogêneas enquanto preserva as bordas entre diferentes feições presentes nas cenas.

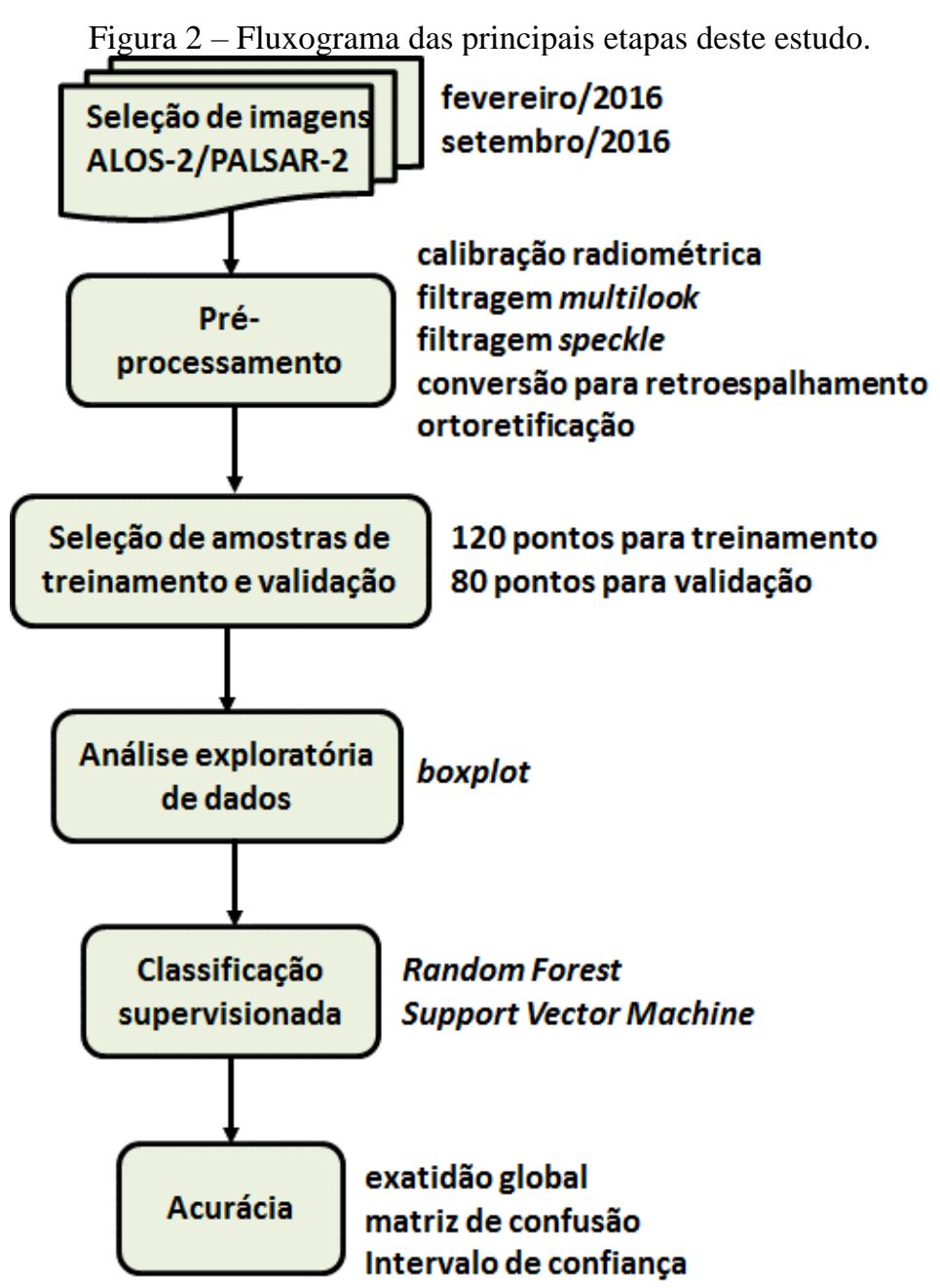

Fonte: Os autores (2021).

Em seguida, foram realizadas as operações matemáticas de multiplicação e divisão de polarizações, gerando-se os produtos $\mathrm{HH}^{*} \mathrm{HV}$ e HH/HV. As imagens obtidas na polarização HH são mais sensíveis do que as obtidas na polarização HV à rugosidade do terreno, por exemplo, aos troncos e galhos deixados no terreno logo após um evento de desmatamento (WATANABE et al., 2018). Ainda de acordo com esses últimos autores, a polarização HV é mais sensível ao dossel florestal do que a polarização HH. Com isso, as imagens resultantes da multiplicação ou divisão entre essas duas polarizações podem realçar melhor os alvos 
que possuem diferentes rugosidades no terreno, em relação às polarizações individuais. Foi gerado ainda o Índice de Retroespalhamento por Diferença Normalizada (NDBI - Normalized Difference Backscatter Index), que corresponde a um índice normalizado derivado dos retroespalhamentos nas polarizações horizontal $(\mathrm{HH})$ e vertical (HV) (Equação 1) (ALMEIDA FILHO et al., 2009; GARCIA et al., 2018). Quanto maior a densidade do dossel vegetal, maior será o NDBI.

$$
N D B I=\frac{\sigma_{H H}^{0}-\sigma_{H V}^{0}}{\sigma_{H H}^{0}+\sigma_{H V}^{0}}
$$

Pesquisas de campo foram conduzidas no período de 24 a 29 de outubro de 2016 para identificar as classes de uso e cobertura de terras mais representativas da área de estudo. Foram visitados 65 pontos amostrais, identificando-se as seguintes classes: floresta primária, principalmente floresta estacional semidecidual; floresta secundária, em estágio intermediário ou avançado de regeneração; cultura agrícola de sequeiro, notadamente soja, milho e algodão; e pastagem cultivada, notadamente pela espécie exótica Brachiaria. Para cada ponto, foram obtidas as coordenadas geográficas com um receptor GPS Garmin Etrex de navegação, além de registro fotográfico panorâmico com uma câmera digital Canon SX50 HS.

Os pontos amostrais obtidos em campo foram complementados com 135 pontos adicionais, selecionados por meio de consulta aos resultados dos Projetos TerraClass Amazônia (ALMEIDA et al., 2016) e MapBiomas (MAPBIOMAS, 2019) para fazer parte das áreas de treinamento para a etapa posterior de classificação supervisionada (Tabela 1). Um conjunto de 41 pontos de floresta secundária foram selecionados do Projeto TerraClass Amazônia, enquanto um total de 32, 18 e 44 pontos de floresta primária, cultura agrícola e pastagem cultivada, respectivamente, foram selecionados do Projeto MaBiomas. As classes desses pontos complementares foram confirmadas por meio de inspeção visual de séries temporais do sensor MODIS convertidos para índices de vegetação realçado (EVI), disponíveis no sistema visualizador de imagens SatVeg - Embrapa Informática Agropecuária (EMBRAPA, 2020).

Tabela 1 - Número de pontos de amostragem para treinamento e validação dos classificadores supervisionados Random Forest e Support Vector Machine. Do conjunto de 200 pontos, foram sorteados 120 pontos para treinamento. Os 80 pontos restantes foram utilizados para análise da acurácia dos resultados da classificação.

\begin{tabular}{l|c|c}
\multicolumn{1}{c}{ Classe } & Inspeção de Campo & Dados auxiliares (Projeto TerraClass Amazônia e Projeto MapBiomas) \\
\hline Floresta primária & 18 & 32 \\
Floresta secundária & 9 & 41 \\
Cultura agrícola & 6 & 44 \\
Pastagem cultivada & 32 & 18 \\
Total & 65 & 135 \\
\hline
\end{tabular}

Fonte: Os autores (2021).

Os pontos amostrais foram expandidos para áreas regulares com tamanho de $60 \mathrm{~m}$ x $60 \mathrm{~m}$ de modo que cada amostra fosse composta por pelo menos 100 pixels em cada cena do ALOS-2/PALSAR-2. Do total de 200 pontos amostrais, foram sorteados 120 pontos para treinamento, enquanto os 80 pontos restantes foram utilizados para análise da acurácia dos resultados das classificações.

Para as análises estatísticas, foram obtidas as médias aritméticas simples de cada conjunto de 120 amostras de treinamento nas imagens HH, HV, HH*HV, HH/HV e NDBI de fevereiro e setembro de 2016, gerando-se, em seguida, os gráficos de boxplots.

As cenas foram classificadas com base nos classificadores SVM e RF, disponíveis no programa ENVI 5.3 e SNAP 6.0, respectivamente. Ambos os classificadores são comumente utilizados em estudos envolvendo imagens de radar na Amazônia (LI et al., 2012; MASCARO et al., 2014; PAVANELLI et al., 2018). No método SVM (CORTES; VAPNIK, 1995), o classificador é treinado para encontrar o hiperplano de separação ótimo por meio da minimização do limite superior do erro de classificação (ADAM et al., 2014; MOREIRA et al., 2014). Para este trabalho, após testes empíricos, foi adotada a função Kernel de base radial com parâmetro Gamma $=1$, parâmetro de penalidade $\mathrm{C}=100$ e parâmetro Classification Probability Threshold $(\mathrm{CTP})=0 . \mathrm{O}$ RF foi proposto por Breiman (2001) para melhorar o desempenho dos classificadores conhecidos como árvores 
de decisão por meio da combinação de várias árvores. Cada árvore contribui com um único voto e a classificação final é determinada pelo maior número de votos dados por cada árvore da floresta (SOTHE et al., 2017). Após testes realizados, os números de amostras e árvores foram de 5.000 e 10, respectivamente.

As acurácias das classificações foram analisadas com base na exatidão global e nas matrizes de confusão (BRITES; SOARES; RIBEIRO, 1996). A partir das amostras de treinamento e de validação e áreas ocupadas por cada classe temática nos resultados das classificações pelos métodos do SVM e RF, foram obtidos os intervalos de confiança com $95 \%$ de probabilidade das respectivas acurácias globais, conforme metodologia proposta por Olofsson et al. (2014) e implementado no pacote estatístico R (R Core Team, 2019).

\section{RESULTADOS E DISCUSSÃO}

Na Figura 3, são mostrados os valores de $\sigma^{\circ}$ relativos às polarizações HH e HV referentes às quatro classes de uso e cobertura de terras da área de estudo. Valores médios de retroespalhamento das florestas primária e secundária para a polarização $\mathrm{HH}$ foram superiores aos da polarização $\mathrm{HV}$, independentemente da estação climática: $-7,42 \mathrm{~dB}$ e -12,03 dB para a floresta primária nas polarizações $\mathrm{HH}$ e $\mathrm{HV}$, respectivamente; e de - 7,53 dB e -12,45 dB para a floresta secundária nas polarizações $\mathrm{HH}$ e HV, respectivamente. Esses valores são bastante próximos aos obtidos, por exemplo, por Aboud Neta (2009) e Almeida Filho et al. (2009).

Os valores mais baixos de retroespalhamento na polarização HV já eram esperados, pois, nas polarizações cruzadas, o retroespalhamento é derivado principalmente do espalhamento volumétrico múltiplo no interior dos dosséis, atenuando o retorno da radiação para a antena do radar (LEWIS; HENDERSON, 1998). Já na polarização paralela $\mathrm{HH}$, predomina o espalhamento superficial no topo do dossel ou na superfície dos solos, resultando em um retorno relativamente mais alto do sinal retroespalhado pelas folhas, troncos, galhos e solos. Por causa dos menores níveis de biomassa das áreas ocupadas com culturas agrícolas e pastagens cultivadas, os valores de retroespalhamento foram menores em relação aos das florestas primária e secundária: $-15,20 \mathrm{~dB}$ e -25,07 dB para a cultura agrícola nas polarizações HH e HV; e -14,81 dB e -22,39 dB para a pastagem cultivada nas polarizações HH e HV, respectivamente.

Os coeficientes de retroespalhamento entre floresta primária e floresta secundária não apresentaram muita discrepância. O mesmo padrão também foi observado para as classes culturas agrícola e pastagem cultivada. A precipitação acumulada de $21 \mathrm{~mm}$ e $72 \mathrm{~mm}$ nos 10 dias anteriores às passagens de satélite em fevereiro e setembro pode ter reduzido a capacidade de discriminação de alvos, por causa do aumento no conteúdo de água nos solos e no dossel vegetal, conforme constatado por Garcia et al. (2018) em cinco áreas de estudo localizadas em dois biomas distintos nos Estados Unidos. No entanto, diferenças significativas foram encontradas entre as classes de cobertura vegetal natural (florestas primária e secundária) e antrópica (culturas agrícolas e pastagens cultivadas), independentemente da polarização ou do mês do ano.

Os desempenhos das imagens resultantes da álgebra de mapas para discriminar as quatro classes de uso e cobertura de terras da área de estudo podem ser observados na Figura 4. A imagem resultante da multiplicação das polarizações $\left(\mathrm{HH}^{*} \mathrm{HV}\right)$ apresentou padrão similar de discriminação mostrado anteriormente na Figura 3. No entanto, baseado na inspeção visual das amplitudes das barras, percebe-se que houve uma piora na discriminação desses quatro alvos tanto para a razão HH/HV como para o NDBI.

Embora os resultados deste estudo indiquem que as imagens NDBI não melhoram o potencial de discriminar diferentes classes de uso e cobertura de terras da área de estudo, esse índice é importante para discriminar áreas onde os desmatamentos são relativamente recentes, isto é, quando a superfície do terreno ainda contém restos de galhos e troncos de árvores e arbustos, causando aumento significativo do retroespalhamento na polarização $\mathrm{HH}$, decorrente do aumento na rugosidade do terreno (ALMEIDA FILHO et al., 2009). De acordo com Watanabe et al. (2018), o aumento nos valores de retroespalhamento é significativamente menor na polarização cruzada HV. Da mesma forma, a divisão de polarizações HH/HV parece ser indicada para detecção de desmatamentos recentes. De fato, a JAXA tem utilizado essa divisão, juntamente com as polarizações $\mathrm{HH}$ e $\mathrm{HV}$, para identificar desmatamentos recentes em 77 países tropicais com coberta florestal (JJ-FAST, 2019). 
Figura 3 - Boxplots das classes de uso e cobertura de terras da área de estudo (floresta primária, floresta secundária, cultura agrícola e pastagem cultivada) envolvendo as polarizações HH e HV dos meses de fevereiro de 2016 e setembro de 2016. Bases inferior e superior dos retângulos representam o primeiro e o terceiro quartil, enquanto a linha horizontal dentro do retângulo representa o segundo quartil (mediana). Barras horizontais acima e abaixo dos retângulos representam valor máximo e mínimo. Símbolo X representa a média, enquanto círculos representam valores anômalos (outliers).

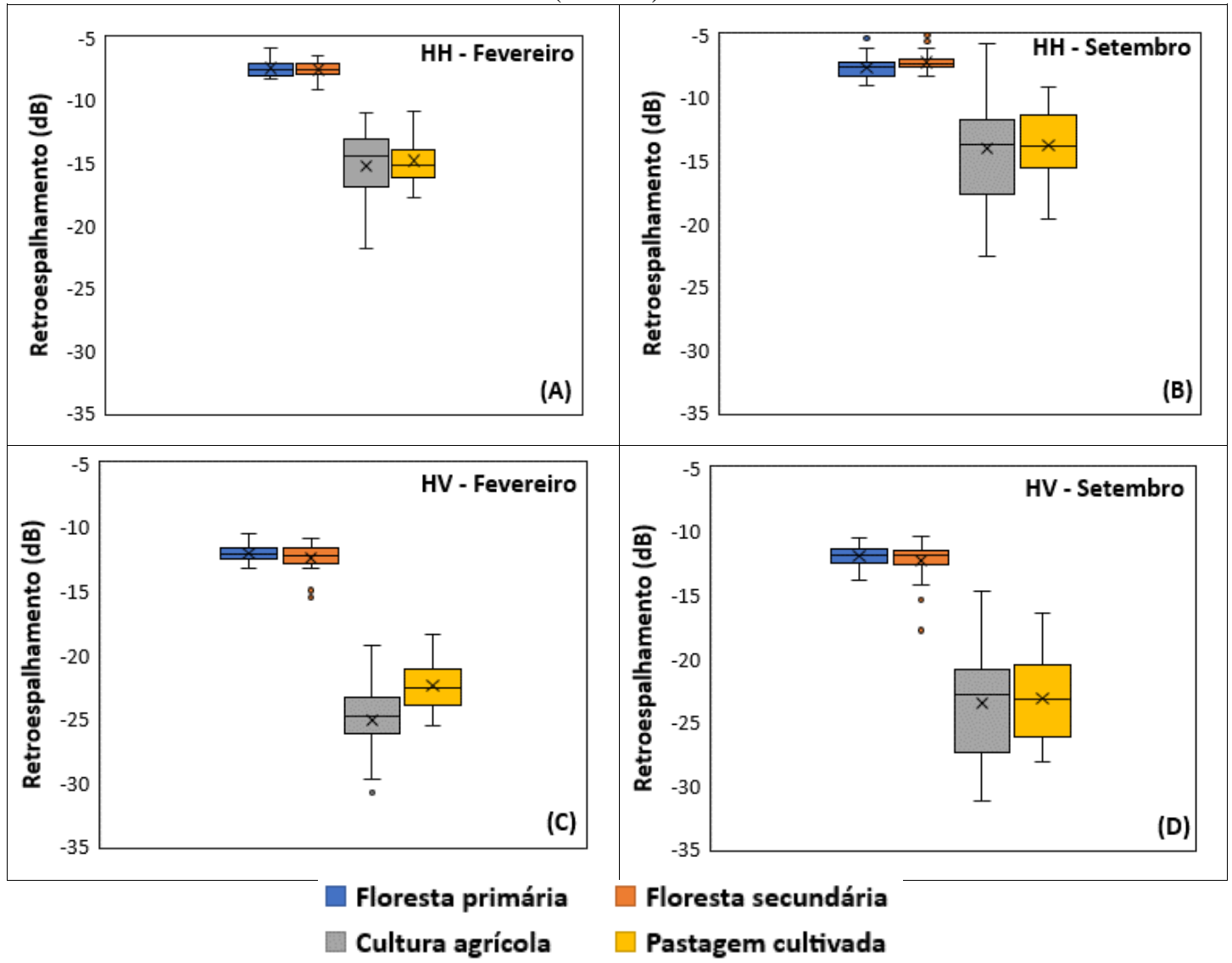

Fonte: Os autores (2021). 
Figura 4 - Boxplots das classes de uso e cobertura de terras da área de estudo (floresta primária, floresta secundária, cultura agrícola e pastagem cultivada) envolvendo as álgebras de mapas $\mathrm{HH}^{*} \mathrm{HH}, \mathrm{HH} / \mathrm{HH}$ e Normalized Difference

Backscattering Index (NDBI) dos meses de fevereiro de 2016 e setembro de 2016.

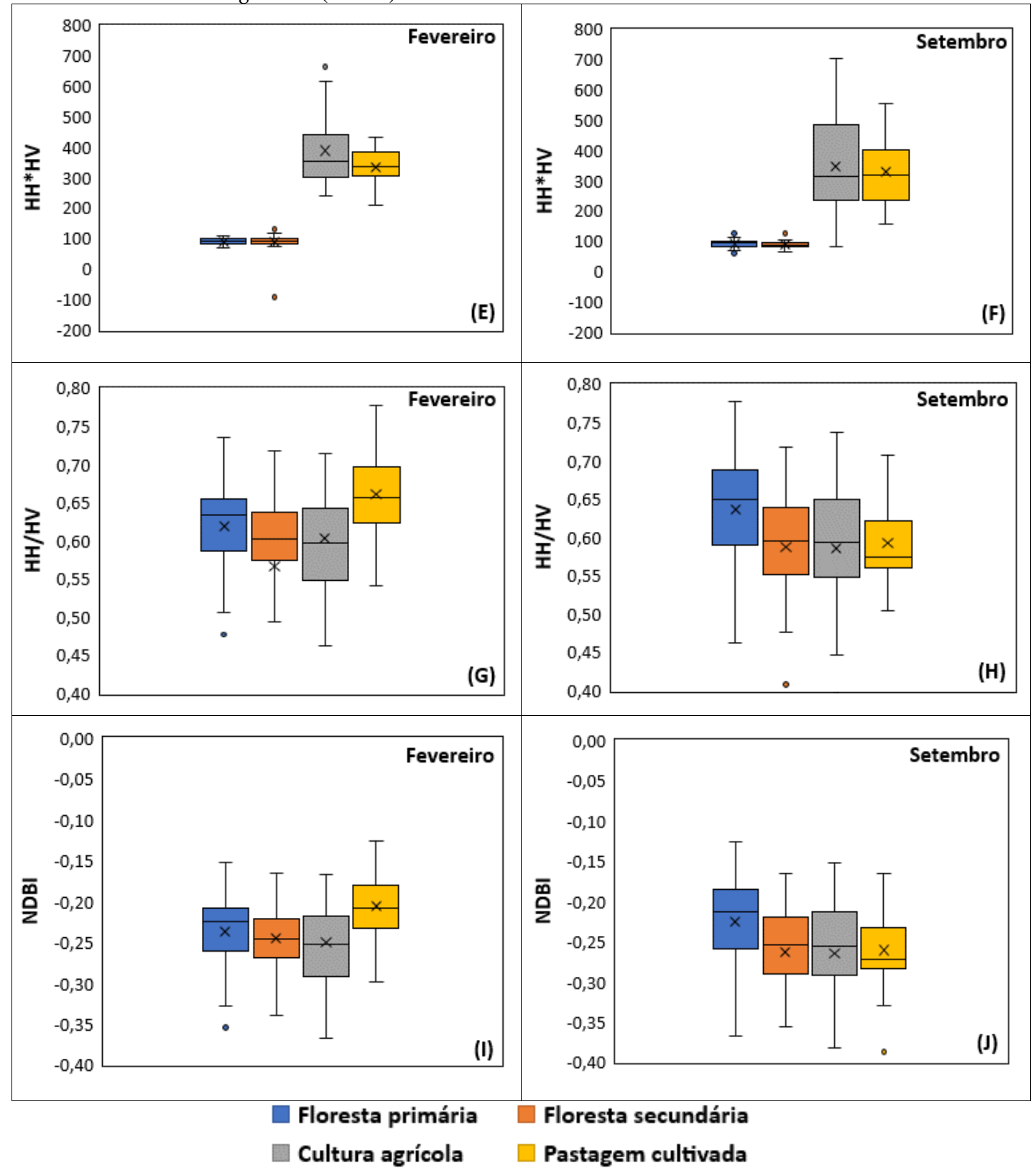

Fonte: Os autores (2021).

A partir das análises estatísticas acima apresentadas, concluiu-se que as cenas que apresentaram os melhores resultados foram $\mathrm{HH}, \mathrm{HV}$ e $\mathrm{HH}^{*} \mathrm{HV}$. As mesmas foram consideradas na etapa subsequente de classificação de imagens. Foram selecionadas as cenas de fevereiro por apresentarem menor dispersão de valores de retroespalhamento, conforme mostrado nos boxplots.

Na Figura 5, é apresentado o resultado da classificação pelo algoritmo SVM. Como já era esperado, houve grande confusão na classificação entre floresta primária e floresta secundária. Em nenhum ponto da imagem foi possível fazer uma separação satisfatória entre essas classes. Prado et al. (2010) também reportaram dificuldade de separar floresta primária de floresta degradada, especialmente na polarização HH do satélite Japanese Earth Resources Satellite (JERS-1) (banda L). Já as classes de cultura agrícola e pastagem apresentaram uma diferenciação ligeiramente superior, podendo-se observar melhor individualização dessas duas classes, conforme ilustrado nos dois recortes ampliados da Figura 5.

A exatidão global da classificação SVM foi de $65 \%$, com correspondente intervalo de confiança a $95 \%$ de probabilidade de $11 \%$ (Tabela 2). A classe floresta secundária apresentou os maiores valores de erro de comissão e omissão, com 55\% e 57,1\% respectivamente. A classe que apresentou o menor erro de omissão e comissão foi a pastagem cultivada. 
Figura 5 - Resultado da classificação supervisionada pelo algoritmo Support Vector Machine, baseada nas polarizações HH, HV e HH*HV do mês de fevereiro de 2016.

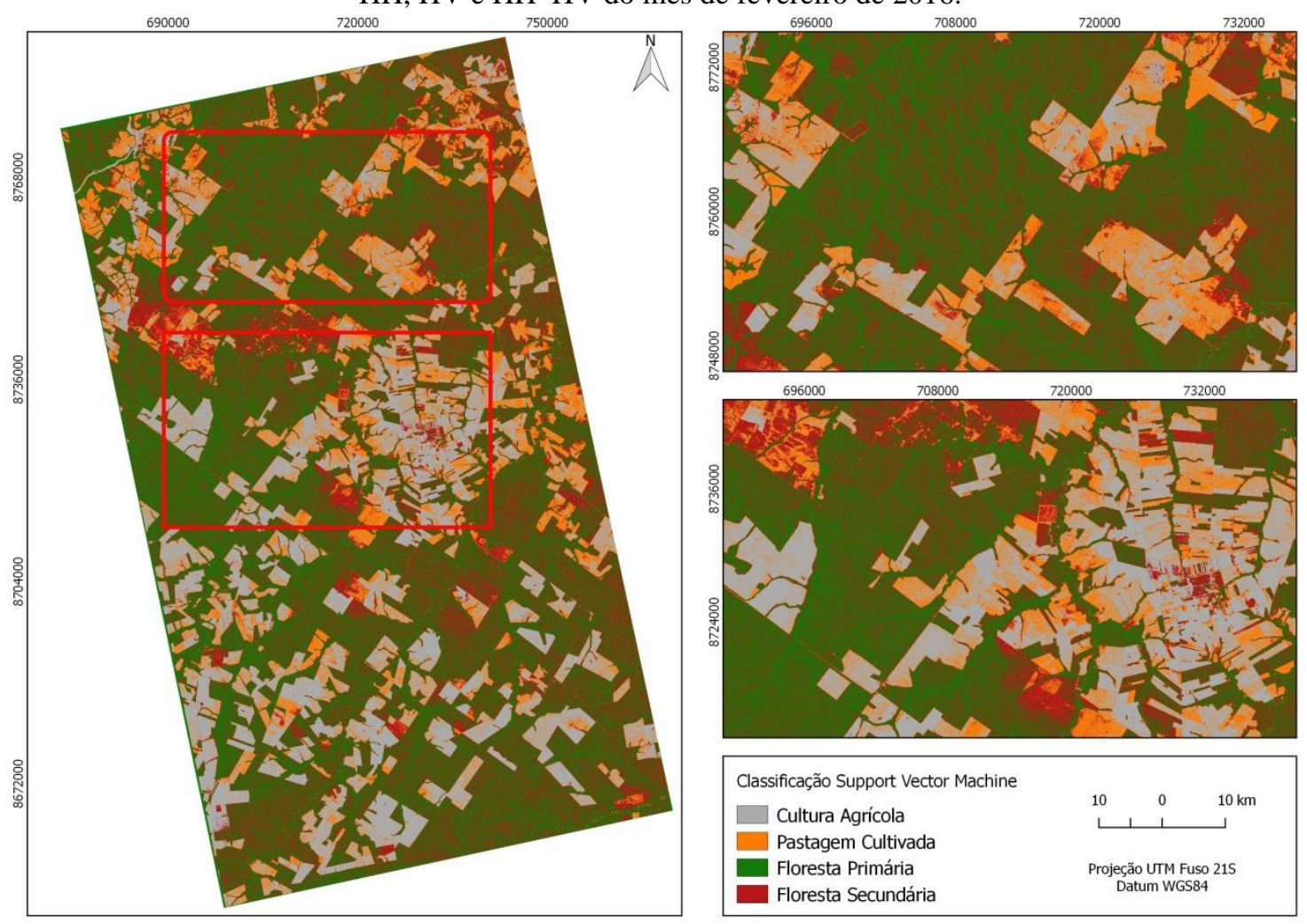

Fonte: Os autores (2021).

Tabela 2 - Matriz de confusão do classificador Support Vector Machine (SVM) envolvendo as polarizações HH, HV e $\mathrm{HH}^{*} \mathrm{HV}$ de fevereiro de 2016. \%EO = porcentagem de erro de omissão; \% EC = porcentagem de erro de comissão.

Exatidão global $=65 \%$ Intervalo de confiança $=11 \%$.

\begin{tabular}{l|c|c|c|c|c|c|c}
\hline \multicolumn{1}{c|}{ Classe } & $\begin{array}{c}\text { Floresta } \\
\text { primária }\end{array}$ & $\begin{array}{c}\text { Floresta } \\
\text { secundária }\end{array}$ & $\begin{array}{c}\text { Cultura } \\
\text { agrícola }\end{array}$ & $\begin{array}{c}\text { Pastagem } \\
\text { cultivada }\end{array}$ & Total & \% EO & \% EC \\
\hline Floresta primária & 14 & 11 & 1 & 0 & 19 & 26,3 & 30,0 \\
Floresta secundária & 6 & 9 & 0 & 2 & 21 & 57,1 & 55,0 \\
Cultura agrícola & 0 & 0 & 14 & 3 & 21 & 33,3 & 30,0 \\
Pastagem cultivada & 0 & 0 & 5 & 15 & 19 & 21,1 & 25,0 \\
Total & 20 & 20 & 20 & 20 & 80 & & \\
\hline
\end{tabular}

Fonte: Os autores (2021).

A classificação resultante do emprego do algoritmo RF é apresentada na Figura 6. Visualmente, é possível perceber que as classes floresta primária e floresta secundária apresentaram maior confusão do que a encontrada pelo classificador SVM. Em contrapartida, as classes cultura agrícola e pastagem cultivada apresentaram uma ligeira melhora na diferenciação. A exatidão global da classificação pelo método RF foi de $74 \%$, com correspondente intervalo de confiança a 95\% de probabilidade de $9 \%$ (Tabela 3). As classes que apresentaram os maiores erros de omissão foram floresta primária e floresta secundária, com 34,6\% e 27,4\%, respectivamente. O maior erro de comissão foi encontrado na floresta secundária, com porcentagem de $40 \%$. As classes cultura agrícola e pastagem apresentaram erros de omissão e comissão inferiores a $30 \%$.

Na Tabela 4, são mostrados os cálculos de áreas ocupadas por floresta primária, floresta secundária, pastagem cultivada e cultura agrícola na área de estudo, obtidos pelos classificadores SVM e RF. As duas classes predominantes foram floresta primária e floresta secundária, vindo a seguir, as culturas agrícolas. 
Figura 6 - Resultado da classificação supervisionada pelo algoritmo Random Forest, polarizações HH, HV e HH*HV

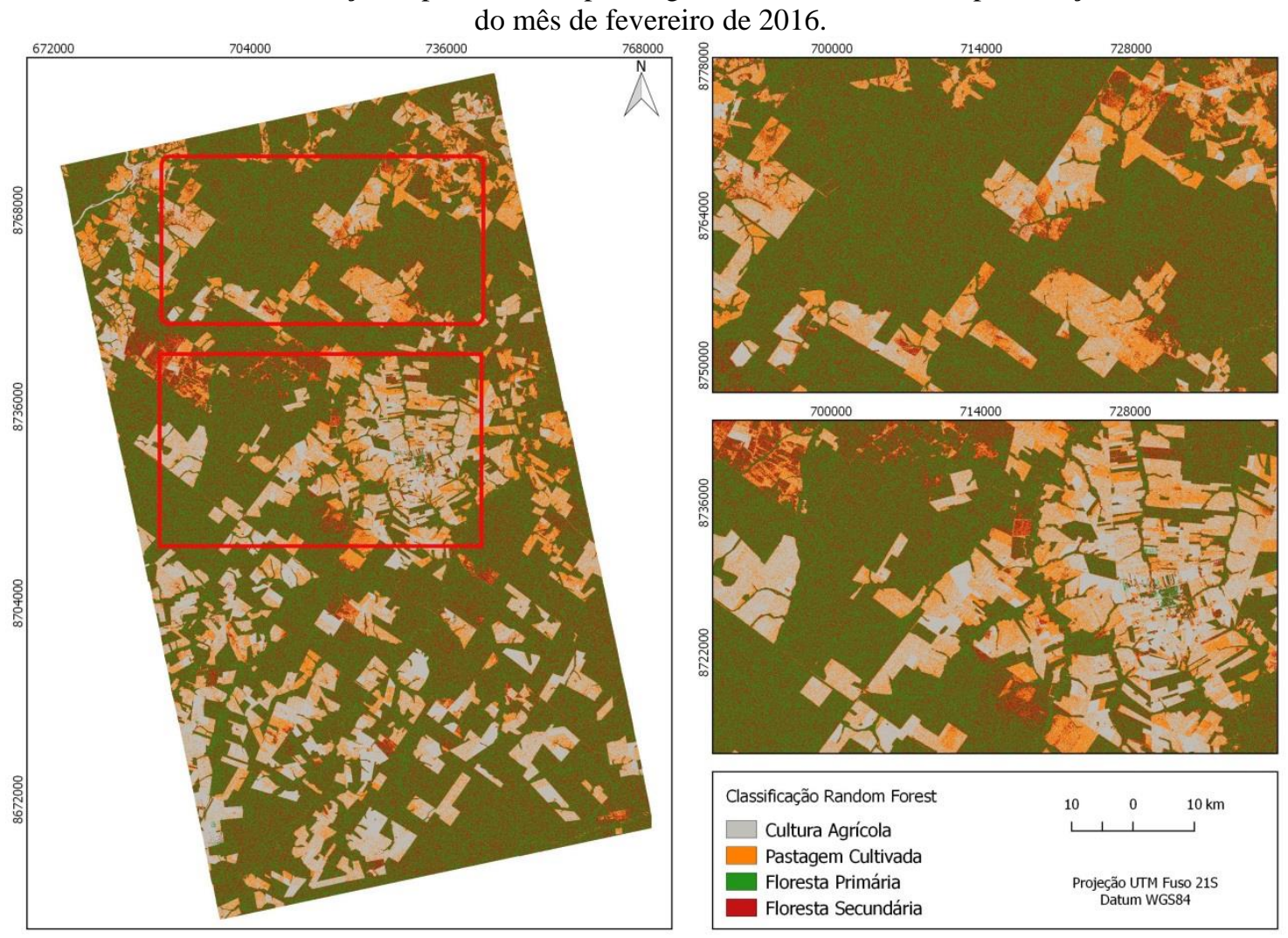

Fonte: Os autores (2021).

Tabela 3 - Matriz de confusão do classificador Random Forest (RF) envolvendo as polarizações HH, HV e HH*HV de fevereiro de 2016. \%EO = porcentagem de erro de omissão; \% EC = porcentagem de erro de comissão; Exatidão global

\begin{tabular}{l|c|c|c|c|c|c|c}
\multicolumn{1}{c|}{ Classe } & $\begin{array}{c}\text { Floresta } \\
\text { primária }\end{array}$ & $\begin{array}{c}\text { Floresta } \\
\text { secundária }\end{array}$ & $\begin{array}{c}\text { Cultura } \\
\text { agrícola }\end{array}$ & $\begin{array}{c}\text { Pastagem } \\
\text { cultivada }\end{array}$ & Total & $\%$ EO & $\%$ EC \\
\hline Floresta primária & 17 & 8 & 1 & 0 & 26 & 34,6 & 15,0 \\
Floresta secundária & 3 & 12 & 0 & 2 & 17 & 27,4 & 40,0 \\
Cultura agrícola & 0 & 0 & 15 & 3 & 18 & 16,6 & 25,0 \\
Pastagem cultivada & 0 & 0 & 4 & 15 & 19 & 21,1 & 25,0 \\
Total & 20 & 20 & 20 & 20 & 80 & & \\
\hline
\end{tabular}

Fonte: Os autores (2021).

Tabela 4 - Áreas ocupadas por floresta primária, floresta secundária, cultura agrícola e pastagem cultivada na região de estudo, estimadas pelos classificadores Support Vector Machine e Random Forest.

\begin{tabular}{l|c|c}
\hline \multirow{2}{*}{\multicolumn{1}{c}{ Classe }} & \multicolumn{2}{|c}{ Área (ha) } \\
\cline { 2 - 3 } & Support Vector Machine & Random Forest \\
\hline Floresta primária & 358.430 & 357.408 \\
Floresta secundária & 255.125 & 268.624 \\
Cultura agrícola & 167.482 & 170.830 \\
Pastagem cultivada & 110.171 & 110.498 \\
Total & 891.208 & 907.360 \\
\hline
\end{tabular}

Fonte: Os autores (2021).

\section{CONSIDERAÇÕES FINAIS}

Este estudo mostrou que é possível discriminar dois grupos de classes de uso e cobertura de terras na região de transição Amazônia/Cerrado no estado de Mato Grosso a partir de análise de imagens de radar do satélite ALOS-2 PALSAR-2 com dupla polarização: floresta primária e floresta secundária; e cultura agrícola e pastagem cultivada. Não houve interferência acentuada da sazonalidade climática no processo de retroespalhamento das imagens obtidas nas estações seca e chuvosa, provavelmente devido à ocorrência de chuvas nos 10 dias anteriores às datas de passagem do satélite. Apesar da acurácia global do RF ter sido superior à do SVM, o desempenho dos dois classificadores foram estatisticamente similares. 
Recomenda-se que esse estudo tenha prosseguimento incorporando técnicas mais complexas de processamento digital de imagens de radar, tais como as técnicas de decomposição de alvos propostas, por exemplo, por Cloude e Pottier (1996) e Yamaguchi et al. (2005). Essas técnicas consideram o mecanismo de retroespalhamento como um somatório de elementos dispersores independentes, associando-se, a cada um desses elementos, um mecanismo físico de espalhamento (CLOUDE; POTTIER, 1996).

\section{Agradecimentos}

Estudo foi desenvolvido parcialmente no âmbito da Iniciativa Kyoto \& Carbono. Os autores agradecem os valiosos comentários de dois revisores anônimos que contribuíram substancialmente para a melhoria da versão final do manuscrito.

\section{Contribuição dos Autores}

A metodologia do trabalho foi definida em conjunto com os autores Vanessa Souza Silva e Edson Eyji Sano. O processamento e a análise de dados foram conduzidos pela autora Vanessa Souza Silva e revisados pelo autor Edson Eyji Sano. Os autores Tati de Almeida e Humberto Navarro Mesquita Júnior estiveram envolvidos na definição da abordagem metodológica e na redação da primeira versão do manuscrito.

\section{Conflitos de Interesse}

Os autores declaram que não há conflitos de interesse.

\section{Referências}

ABOUD NETA, S. R. Uso de imagens ALOS/PALSAR multipolarizadas para detecção de incremento de desflorestamento na Amazônia. Dissertação (Mestrado em Sensoriamento Remoto) - Instituto Nacional de Pesquisas Espaciais, São José dos Campos, 2009, 264 p.

ABOUD NETA, S. R.; FREITAS, C. C.; DUTRA, L. V. Uso de imagem ALOS/PALSAR multipolarizadas para detecção de incremento de desflorestamento na Amazônia. Revista Brasileira de Cartografia, n. 62, p. 417-431, 2010.

ADAM, E.; MUTANGA, O.; ODINDI, J.; ABDEL-RAHMAN, E. M. Land use/cover classification in a heterogeneous coastal landscape using RapidEye imagery: evaluating the performance of random forest and support vector machines classifiers. International Journal of Remote Sensing, v. 35, n. 10, p. 34403458, 2014. DOI: 10.1080/01431161.2014.903435.

AGRITEMPO. Sistema de monitoramento agrometeorológico. Disponível em: <https://www.agritempo.gov.br/agritempo/index.jsp>. Acesso em: 19 set. 2018.

ALENCAR, L. A.; ALMEIDA, L. V. C.; PIGNATI, W. A.; PIGNATTI, M. G. População, desmatamento e produção agrícola temporária na área de influência da BR-163 - Mato Grosso. In: MARANDOLA Jr., E.; D’Antonna, A. O.; OJIMA, R. (Orgs.). População, Ambiente e Desenvolvimento. Mudanças Climáticas e Urbanização no Centro-Oeste. $1^{\text {a }}$ ed. Campinas: Nepo/Unicamp; Brasília: UNFPA, 192 p., 2011.

ALMEIDA, C. A.; COUTINHO, A. C.; ESQUERDO, J. C. D. M.; ADAMI, M.; VENTURIERI, A.; DINIZ, C. G.; DESSAY, N.; DURIEUX, L.; GOMES, A. R. High spatial resolution land use and land cover mapping of the Brazilian Legal Amazon in 2008 using Landsat-5/TM and MODIS data. Acta Amazonica, v. 46, n. 3, p. 291-302, 2016. DOI: 10.1590/1809-4392201505504.

ALMEIDA-FILHO, R.; ROSENQVIST, A.; SHIMABUKURO, Y. E.; SANTOS, J. R. Evaluation and perspctives of using multitemporal L-band SAR data to monitor deforestation in the Brazilian Amazônia. IEEE Geoscience and Remote Sensing Letters, v. 2, n. 4, p. 409-412, 2005. DOI: 10.1109/LGRS.2005.856679. 
ALMEIDA FILHO, R.; SHIMABUKURO, Y. E.; ROSENQVIST, A.; SÁNCHEZ, G. A. Using dual-polarized ALOS PALSAR data for detecting new fronts of deforestation in the Brazilian Amazônia. International Journal of Remote Sensing, v. 30, n. 14, p. 3735-3743, 2009. DOI: 10.1080/01431160902777175.

ARVOR, D.; JONATHAN, M.; MEIRELLES, M. S. P.; DUBREUIL, V.; DURIEUX, L. Classification of MODIS EVI time series for crop mapping in the state of Mato Grosso, Brazil. International Journal of Remote Sensing, v. 32, n. 22, p. 7847-7871, 2011. DOI: 10.1080/01431161.2010.531783.

ASNER, G. P. Cloud cover in Landsat observations of the Brazilian Amazon. International Journal of Remote Sensing, v. 22, n. 18, p. 3855-3862, 2001. DOI: 10.1080/01431160010006926.

BREIMAN, L. Random Forests. Machine Learning, v. 45, n. 1, p. 5-32. 2001. DOI: 10.1023/A:1010933404324.

BRITES, R. S.; SOARES, V. P.; RIBEIRO, C. A. A. S. Verificação da exatidão em classificação de uma imagem orbital mediante a utilização de três índices. Revista Árvore, v. 20, n. 3, p. 415-424, 1996.

BROWN, J. C.; KASTENS, J. H.; COUTINHO, A. C.; VICTORIA, D. C.; BISHOP, C. R. Classifying multiyear agricultural land use data from Mato Grosso using time-series MODIS vegetation index data. Remote Sensing of Environment, v. 130, p. 39-50, 2013. DOI: 10.1016/j.rse.2012.11.009.

CARREIRAS, J. M. B.; JONE, J.; LUCAS, R. M.; SHIMABUKURO, Y. E. Mapping major land cover types and retrieving the age of secondary forests in the Brazilian Amazon by combining single-date optical and radar remote sensing data. Remote Sensing of Environment, v. 194, p. 16-32, 2017. DOI: 10.1016/j.rse.2017.03.016.

CLOUDE, S. R.; POTTIER, E. A review of target decomposition theorems in radar polarimetry. IEEE Transactions on Geoscience and Remote Sensing, v. 34, p. 498-518, 1996. DOI: 10.1109/36.485127.

CORTES, C.; VAPNIK, V. Support-vector networks. Machine Learning, v. 20, p. 273-297, 1995. DOI: 10.1007/BF00994018.

EMBRAPA. SATVeg v. 3.3. Campinas: Embrapa Informática Agropecuária. Disponível em: https://www.satveg.cnptia.embrapa.br/satveg/pages/home.html?faces-redirect=true \& includeViewParams=true. Acesso em: 13 mai. 2020.

GARCIA, M.; SAATCHI, S.; USTIN, S.; BALZTER, H. Modelling forest canopy height by integrating airborne LiDAR samples with satellite radar and multispectral imagery. International Journal of Applied Earth Observation and Geoinformation, v. 66, n. 8, p. 159-163, 2018. DOI: 10.1016/j.jag.2017.11.017.

GIBBS, H. K.; RAUSCH, L.; MUNGER, J.; SCHELLY, I.; MORTON, D. C.; NOOJIPADY, P.; SOARESFILHO, B.; BARRETO, P.; MICOL, L.; WALKER, N.F. Brazil's soy moratorium. Science, v. 347, n. 6220, p. 377-378, 2015. DOI: 10.1126/science.aaa0181.

GOLLNOW, F.; HISSA, L. B. V.; RUFIN, P.; LAKES, T. Property-level direct and indirect deforestation for soybean production in the Amazon region of Mato Grosso, Brazil. Land Use Policy, v. 78, p. 377-385, 2018. DOI: 10.1016/j.landusepol.2018.07.010.

GRIFFITHS, P.; JAKIMOW, B.; HOSTERT, P. Reconstructing long term annual deforestation dynamics in Pará and Mato Grosso using the Landsat archive. Remote Sensing of Environment, v. 216, p. 497-513, 2018. DOI: $10.1016 /$ j.rse.2018.07.010.

INSTITUTO BRASILEIRO DE GEOGRAFIA E ESTATÍSTICA (IBGE). Mapa de biomas e de vegetação. 2004. Rio de Janeiro: IBGE. Disponível em: <https://ww2.ibge.gov.br/home/presidencia/noticias/21052004biomashtml.shtm>. Acesso em: 29 abr. 2019.

INSTITUTO BRASILEIRO DE GEOGRAFIA E ESTATÍSTICA (IBGE). Censo Agropecuário 2017a. Resultados preliminares. Rio de Janeiro: IBGE. Disponível em: <https://censos.ibge.gov.br/agro/2017/templates/censo_agro/resultadosagro/index.html>. Acesso em: 29 abr. 2019.

INSTITUTO BRASILEIRO DE GEOGRAFIA E ESTATÍSTICA (IBGE). Produção agrícola municipal - 
PAM. 2017b. Rio de Janeiro: IBGE Disponível em: <https://www.ibge.gov.br/estatisticas/economicas/agricultura-e-pecuaria/9117-producao-agricolamunicipal-culturas-temporarias-e-permanentes.html?=\&t =resultados>. Acesso em: 29 abr. 2019.

INSTITUTO BRASILEIRO DE GEOGRAFIA E ESTATÍSTICA (IBGE). Pesquisa da pecuária municipal - PPM. 2017c. Rio de Janeiro: IBGE. Disponível em: <https://www.ibge.gov.br/estatisticas/economicas/agricultura-e-pecuaria/9107-producao-da-pecuariamunicipal.html?=\&t=resultados>. Acesso em: 29 abr. 2019.

INSTITUTO BRASILEIRO DE GEOGRAFIA E ESTATÍSTICA (IBGE). Projeto RADAMBRASIL. Disponível em: <https://mapas.ibge.gov.br/ bases-e-referenciais/bases-cartograficas/cartas>. Acesso em: 20 set. 2018.

JJ-FAST. JICA-JAXA Forest Early Warning System in the Tropics. Tóquio: JAXA, 2019. Disponível em: <https://www.eorc.jaxa.jp/jjfast/>. Acesso em: 29 abr. 2019.

KASTENS, J. H.; BROWN, J. C.; COUTINHO, A. C.; BISHOP, C. R.; ESQUERDO, J. C. D. M. Soy moratorium impacts on soybean and deforestation dynamics in Mato Grosso, Brazil. PloS ONE, v. 12, n. 4, e0176168, 21 p., 2017. DOI: 10.1371/journal.pone.0176168.

KÖPPEN, W. Das geographische system der klimate. In: KÖPPEN, W.; GEIGER, R. (Eds.): Handbuch der Klimatologie. - Gebruder Borntrager, Berlim, v. 1, p. 1-44, Part C, 1936.

LAPINI, A.; PETTINATO, S.; SANTI, E.; PALOSCIA, S.; FONTANELLI, G.; GARZELLI, A. Comparison of machine learning methods applied to SAR images for forest classification in Mediterranean areas. Remote Sensing, v. 12, 369, 2020. DOI: 10.3390/rs12030369.

LEWIS, A. J.; HENDERSON, F. M. Radar fundamentals: the geosciences perspective. In: HENDERSON, F. M.; LEWIS, A. J. (Eds.), Principles and Applications of Imaging Radar. Manual of Remote Sensing. Nova York: John Wiley \& Sons, $3^{\text {a }}$ ed., v. 2, Cap. 3, p. 131-181, 1998.

LI, G.; LU, D.; MORAN, E.; DUTRA, L.; BATISTELLA, M. A comparative analysis of ALOS PALSAR Lband and RADARSAT-2 C-band data for land-cover classification in a tropical moist region. ISPRS Journal of Photogrammetry and Remote Sensing, v. 70, p. 26-38, 2012. DOI: 10.1016/j.isprsjprs.2012.03.010.

MACEDO, M. N.; DeFRIES, R. S.; MORTON, D. C.; STICKLER, C. M.; GALFORD, G. L.; SHIMABUKURO, Y. E. Decoupling of deforestation and soy production in the southern Amazon during the late 2000s. Proceedings of the National Academy of Sciences, v. 109, n. 4, p. 1341-1346, 2012. DOI: 10.1073/pnas.1111374109.

MAPBIOMAS. MapBiomas v. 3.1. Disponível em: 〈http://mapbiomas.org/\#>. Acesso em: 30 abr. 2019.

MARTINS, V. S.; NOVO, E. M. L. M.; LYAPUSTIN, A.; ARAGÃO, L. E. O. C.; FREITAS, S. R.; BARBOSA, C. C. F. Seasonal and interannual assessment of cloud cover and atmospheric constituents across the Amazon (2000-2015): Insights for remote sensing and climate analysis. ISPRS Journal of Photogrammetry and Remote Sensing, v. 145, p. 309-327, 2018. DOI: 10.1016/j.isprsjprs.2018.05.013.

MASCARO, J.; ASNER, G. P.; KNAPP, D. E.; KENNEDY-BOWDOIN, T.; MARTIN, R. E.; ANDERSON, C.; HIGGINS, M.; CHADWICK, K. D. A tale of two "forests": Random forest machine learning aids tropical forest carbon mapping. PloS ONE, v. 9, n. 1, e85993, 2014. DOI: 10.1371/journal.pone.0085993.

MITTERMEIER, R. A.; MITTERMEIER, C. G.; BROOKS, T. M.; PILGRIM, J. D.; KONSTANT, W. R.; FONSECA, G. A. B.; KORMOS, C. Wilderness and biodiversity conservation. Proceedings of the National Academy of Sciences, v. 100, n. 18, p. 10309-10313, 2003. DOI: 10.1073/pnas.1732458100.

MOREIRA, A. A.; FERNANDES, F. H. S.; ALMEIDA, R. P.; NERY, C. V. M. O algoritmo Support Vector Machine aplicado ao mapeamento do uso e ocupação do solo. Revista Brasileira de Geografia Física, v. 7, n. 2, p. 291-303, 2014. DOI: 10.26848/rbgf.v7.2.p291-303.

MÜLLER, H.; GRIFFITHS, P.; HOSTERT, P. Long-term deforestation dynamics in the Brazilian Amazon uncovering historic frontier development along the Cuiabá-Santarém highway. International Journal of Applied Earth Observation and Geoinformation, v. 44, p. 61-69, 2016. DOI: 
10.1016/j.jag.2015.07.005.

MÜLLER, H.; RUFIN, P.; GRIFFITHS, P.; HISSA, L. B. V.; HOSTERT, P. Beyond deforestation: differences in long-term regrowth dynamics across land use regimes in southern Amazonia. Remote Sensing of Environment, v. 86, p. 652-662, 2016. DOI: 10.1016/j.rse.2016.09.012.

MYERS, N.; MITTERMEIER, R. A.; MITTERMEIER, C. G.; FONSECA, G. A. B.; KENT, J. Biodiversity hotspots for conservation priorities. Nature, v. 403, p. 853-858, 2000. DOI: 10.1038/35002501.

OLOFSSON, P.; FOODY, G. M.; HEROLD, M.; STEHMAN, S. V.; WOODCOCK, C. E.; WULDER, M. A. Good practices for estimating area and assessing accuracy of land change. Remote Sensing of Environment, v. 148, p. 42-57, 2014. DOI: 10.1016/j.rse.2014.02.015.

PAVANELli, J. A. P.; SANTOS, J. R.; GALVÃO, L. S.; XAUD, M.; XAUD, H. A. M. PALSAR-2/ALOS2 and OLI/Landsat- 8 data integration for land use and land cover mapping in northern Brazilian Amazon. Boletim de Ciências Geodésicas, v. 24, n. 2, p. 250-269, 2018. DOI: 10.1590/s198221702018000200017.

PEREIRA, L. O.; FREITAS, C. C.; SANT'ANNA, S. J. S.; REIS, M. S. ALOS/PALSAR data evaluation for land use and land cover mapping in the Amazon region. IEEE Journal of Selected Topics in Applied Earth Observations and Remote Sensing, v. 9, n. 12, p. 5413-5423, 2016. DOI: 10.1109/JSTARS.2016.2622481.

PICOLI, M. C. A.; CAMARA, G.; SANCHES, I.; SIMÕES, R.; CARVALHO, A.; MACIEL, A.; COUTINHO, A.; ESQUERDO, J.; ANTUNES, J.; BEGOTTI, R. A.; ARVOR, D.; ALMEIDA, C. Big Earth observation time series analysis for monitoring Brazilian agriculture. ISPRS Journal of Photogrammetry and Remote Sensing, v. 145, p. 328-339, 2018. DOI: 10.1016/j.isprsjprs.2018.08.007.

PÔSSA, E. M.; GAMA, F. F.; SANTOS, J. R.; MURA, J. C.; BISPO, P. C. Análise de uso da terra e cobertura florestal na Amazônia Central, a partir de dado polarimétrico PALSAR/ALOS-1 e coerência interferométrica TanDEM-X. Revista Brasileira de Geografia Física, v. 11, n. 6, p. 2094-2108, 2018. DOI: 10.26848/rbgf.v11.6.p2094-2108.

PRADO, B. R.; MARTINS, V. A.; HAYAKAWA, E. H.; TAVARES JÚNIOR, J. B.; SHIMABUKURO, Y. E. Identificação de classes de cobertura da terra na Amazônia utilizando imagens ALOS/PALSAR e classificação orientada a objetos. Revista Brasileira de Cartografia, v. 62, n. 3, p. 563-569, 2010.

PULELlA, A.; SANTOS, R. A.; SICA, F.; POSOVSZKY, P.; RIZZOLI, P. Multi-temporal Sentinel-1 backscatter and coherence for rainforest mapping. Remote Sensing, v. 12, 847, 2020. DOI: 10.3390/rs 12050847.

R CORE TEAM. R: A language and environment for statistical computing. Viena: R Foundation for Statiscial Computing, 2019.

ROSENQVIST, A.; SHIMADA, M.; LUCAS, R.; CHAPMAN, B.; PAILLOU, P.; HESS, L.; LOWRY, J. The Kyoto \& Carbon Initiative - a brief summary. IEEE Journal of Selected Topics in Applied Earth Observations and Remote Sensing, v. 3, n. 4, p. 551-553, 2010. DOI: 10.1109/JSTARS.2010.2086270.

ROSENQVIST, A.; SHIMADA, M.; SUZUKI, S.; OHGUSHI, F.; TADONO, T.; WATANABE, M.; TSUZUKU, K.; WATANABE, T.; KAMIJO, S.; AOKI, E. Operational performance of the ALOS global systematic acquisition strategy and observation plans for ALOS-2 PALSAR-2. Remote Sensing of Environment, v. 155, p. 3-12, 2014. DOI: 10.1016/j.rse.2014.04.011.

SANO, E. E.; MENESES, P. R.; ALMEIDA, T. Reflectância dos alvos na faixa de micro-ondas. In: MENESES, P. R.; ALMEIDA, T.; BAPTISTA, G. M. M. (Orgs.). Reflectância dos Materiais Terrestres. Análise e Interpretação. São Paulo: Oficina de Textos, Cap. 10, p. 291-315, 2019.

SHIMABUKURO, Y. E.; BEUCHLE, R.; GRECCHI, R. C.; ACHARD, F. Assessment of forest degradation in Brazilian Amazon due to selective logging and fires using time series of fraction images derived from Landsat ETM+ images. Remote Sensing Letters, v. 5, n. 9, p. 773-782, 2014. DOI: 10.1080/2150704X.2014.967880.

SILVA JÚNIOR, C. A.; LIMA, M. Soy moratorium in Mato Grosso: deforestation undermines the agreement. 
Land Use Policy, v. 71, p. 540-542, 2018. DOI: 10.1016/j.landusepol.2017.11.011.

SOARES-FILHO, B.; RAJÃO, R.; MACEDO, M.; CARNEIRO, A.; COSTA, W.; COE, M.; RODRIGUES, H.; ALENCAR, A. Cracking Brazil's forest code. Science, v. 344, p. 363-364, 2014. DOI: 10.1126/science. 1246663.

SOTHE, C.; LIESENBERG, V.; ALMEIDA, C. M.; SCHIMALSKI, M. B. Abordagens para classificação do estádio sucessional da vegetação do Parque Nacional de São Joaquim empregando imagens Landsat-8 e RapidEye. Boletim de Ciências Geodésicas, v. 23, n. 3, p. 389-404, 2017. DOI: 10.1590/s198221702017000300026.

VICTORIA, D. C.; PAZ, A. R.; COUTINHO, A. C.; KASTENS, J.; BROWN, J. C. Cropland area estimates using MODIS NDVI time series in the state of Mato Grosso, Brazil. Pesquisa Agropecuária Brasileira, v. 47, n. 9, p. 1270-1278, 2012. DOI: 10.1590/S0100-204X2012000900012.

WATANABE, M.; KOYAMA, C. N.; HAYASHI, M.; NAGATANI, I.; SHIMADA, M. Early-stage deforestation detection in the tropics with L-band SAR. IEEE Journal of Selected Topics in Applied Earth Observations and Remote Sensing, v. 11, n. 6, p. 2127-2133, 2018. DOI: 10.1109/JSTARS.2018.2810857.

WIEDERKEHR, N. C.; GAMA, F. F.; SANTOS, J. R.; BISPO, P. C.; SANO, E. E. Analysis of the target decomposition technique attributes and polarimetric ratios to discriminate land use and land cover classes of the Tapajós region. Boletim de Ciências Geodésicas, v. 25, n. 1, e2019002, 2019. DOI: 10.1590/s198221702019000100002.

WOODHOUSE, I. H.; MITCHARD, E. T. A.; BROLLY, M.; MANIATIS, D.; RYAN, C. M. Radar backscatter is not a "direct measure" of forest biomass. Nature Climate Change, v. 2, p. 556-557, 2012. DOI: $10.1038 /$ nclimate1601.

YAMAGUCHI, Y.; MORIYAMA, T.; ISHIDO, M.; YAMADA, H. Four-component scattering model for polarimetric SAR image decomposition. IEEE Transactions on Geoscience and Remote Sensing, v. 43, p. 1699-1706, 2005. DOI: 10.1109/TGRS.2005.852084.

ZHU, C.; LU, D.; VICTORIA, D.; DUTRA, L. V. Mapping fractional cropland distribution in Mato Grosso, Brazil using time series MODIS Enhanced Vegetation Index and Landsat Thematic Mapper data. Remote Sensing, v. 8, n. 22, 14 p., 2016. DOI: 10.3390/rs8010022.

\section{Biografia do autor principal}

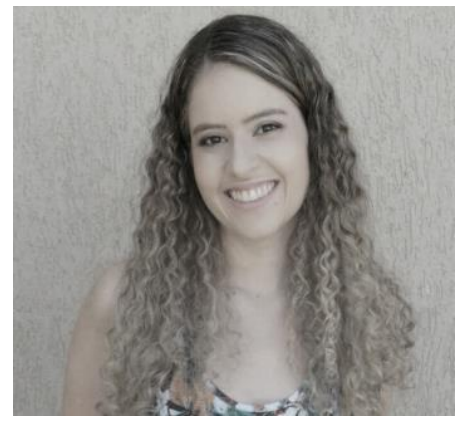

Vanessa Souza Silva, brasileira, natural de Paracatu/MG. Possui graduação (bacharel) em Gestão Ambiental (2012), Especialização em Geoprocessamento Ambiental (2013) e Mestrado em Geociências Aplicadas, área de Geoprocessamento e Análise Ambiental (2019), todos concluídos pela Universidade de Brasília - UnB. No mestrado desenvolveu estudo voltado à detecção de mudanças e evolução do meio ambiente utilizando imagens de radar. Possui experiência em geoprocessamento. Interesse de pesquisa: Mudanças Climáticas; Sensoriamento Remoto; Processamento Digital de Imagens de Satélite; Geoprocessamento; Análises Ambientais.

Esta obra está licenciada com uma Licença Creative Commons Atribuição 4.0 Internacional - CC BY. Esta licença permite que outros distribuam, remixem, adaptem e criem a partir do seu trabalho, mesmo para fins comerciais, desde que lhe atribuam o devido crédito pela criação original. 